\title{
Research Project Model Canvas
}

\author{
Hiago Silva*, Alexandre Cardoso \\ Faculty of Electrical Engineering, Federal University of Uberlandia, Brazil
}

Copyright $\bigcirc 2019$ by authors, all rights reserved. Authors agree that this article remains permanently open access under the terms of the Creative Commons Attribution License 4.0 International License

\begin{abstract}
This work presents a proposal of a visual tool to assist the creation of academic research projects, dissertations and theses. Its metrics are based on business and management success cases. In the creation and management of projects in teams are used visual strategies to present and record the parameters involved in the scope of the project through a screen, which can be composed of a frame with predefined fields or connection lines forming a flowchart. There are tools that can provide researchers with the conditions to view isolated parts of the project as bibliographic references only or correlation nodes between keywords, then it becomes necessary to create a strategy that enables the creator of the project and the team involved to visualize the essence of the project in the eminence of being created and to predict needs, failures, objectives as well as to restructure the project to adapt the research conditions. This strategy has the form of a framework, called Research Project Model Canvas with fields defined according to the needs of creating a research project, and its tables are organized in a logical order of reading, presentation and connection between each one.
\end{abstract}

Keywords Project Framework, Management, Creation, Research Project

\section{Introduction}

During the academic training students learn to do projects since primary school, looking primarily as fun, because they are purposely chosen themes to increase learning interest, and with evolution in the training cycle the projects become denser and with more character technician. When arriving in higher education the student has a baggage of uncountless design models, reports document templates and text templates for the same situation. This student's exposure to a non-standardization of creation contributes with the learning process since each student chooses his / her preferred model, but it makes communication and integration more difficult with other people and projects when it is time to make public, work as a team or consolidate the work in the form of an official document [1].

In the context of business as well as project management, there are specific models to act in the process of generating projects and business in teams, considering teams composed minimum two members, the purpose is that the idea of the project can be conceived, translated of the mental model of each one and recorded on a screen in a more fluid and equivalent way.

In the previous paragraph, it refers to the ability of everyone on the team to be aware of and synchronized in the process of generating ideas and projects, regardless of the position assigned to the team [2]. This equivalence is adjusted by using a canvas as a visual model of the idea, since the topics of the standard writing model are not covered, such as introduction, objectives, methodologies and so on. So, the conceptual aspects of the research project as well as its future conception and finalization are discussed.

There are standard models of each area for project design such as "business plan", "action plan" and "dissertation model" that describe linearly in the form of a textual document all the already designed aspects of the project that one wishes to register. Usually these documents are written during or after the execution of the project, and when they are elaborated before the same happens there is already a great basement of information [3].

\section{Concepts}

To better understand the visual strategy presented in this work, it is necessary to connect three areas of study: Information Visualization, Project Management and Idea Generation with the Brainstorming methodology. These separate areas are great sources of knowledge and each one has its own tools and methodologies to apply its concepts, however, the presented model canvas proposes the interaction of the same simultaneously in a visual tool.

\subsection{Information Visualization}

Visualization of information is truly an interdisciplinary 
field of study. It maintains strong ties with several fields of research, especially information retrieval and geographic information systems [4].

The basic and primary purpose behind any visualization is always the same: from a large volume of data extract the maximum amount of information in a fast, clear and precise way. For this, the most appropriated visual metaphors are used. There are several areas of knowledge that need it: medicine, physics, geology, accounting, economics, administration, etc. On the other hand, the technology is vital to its future (e.g.: the next generations of - PCs, storage systems, display devices, communication systems, analytical tools) as well as a better understanding of the psychological, physical and cognitive processes [3].

\subsection{Project Management}

In a project no matter its content, practical or theoretical is defined by a set of temporary activities, carried out in groups, designed to produce a unique product, service or result [5].

Therefore it requires that it be coordinated and managed, so there are rules, project management strategies according to the context and needs, and it is up to the manager to apply knowledge, skills and techniques to execute projects effectively. It is a strategic competence for organizations, allowing them to combine project results with business objectives - and thus better compete in their markets [7].

\subsection{Ideas Generation with Brainstorming Methodology}

A brainstorming is a situation in which a group of people meet to generate new ideas and solutions around a specific domain of interest, removing inhibitions [6].

This idea-generating practice is applied not only to creating the new, but also to solving problems that the usual ways of solving do not work, so a dedicated team is built to generate solutions without inhibitions.

\section{Related Frameworks}

As this work proposes a methodology linked to a digital tool, it is necessary to compare consolidated models of Information Visualization, Project Management and Idea Generation frameworks that are used via digital tools with the proposition of the Project Model Canvas Research to understand the limits of performance with better efficiency of each.

\subsection{Mind Maps}

One methodology that work the translation process of what is formed as an idea and what is composed of information within a person's thinking to a screen with words and connections, the mental map creation tools that can be used with a specific or freely available methodology. The use of a mental map with the defined method is to create a center node of the screen with the base theme of what will be worked and with branches the terms related to the nearest node are added and can be divided by color or location.

In a freeway, mental maps can contain texts, images and other possible items to insert, considering only the connection between what is proposed in the central node and the branches. This way is commonly used in the process of self-learning, when the creator of the mental map writes everything that has knowledge about the theme that is branched and continues to enlarge the map by inserting as much information as possible. [7].

The advantage of the use is the ability of the creator to expose his or her way of information and how it relates and then visualize this mental construction on a subject in a unique and totalitarian way. But this advantage becomes a negative point when the creator of the mental map does not have knowledge or practice about its use and because there is no mental map template for research projects the creator of the mental map can make it unfeasible to lose in the subject or do not complete all the essential points.

\subsection{Flow Chart}

The flowchart is a visual strategy that represents the flow and binding that the recorded information should follow, and may contain decision points between "yes" and "no" or other options that branch out according to the possibilities.

This methodology is widely applied in industrial processes and decision processes, and the latter aspect correlates with academic research projects, due to the fact that a flowchart has adherence to the context of scientific research, starting from an established starting point and following paths who need a decision.

By using this methodology the teams can map where and when the information is and what the next steps will be. An advantage of this method of describing a project and its parameters is the totalitarian view of where the information will go and how it will be worked out. On the other hand, it is a methodology of exposing information and its connections, and in the context of academic research projects becomes more laborious for not having a defined line of work for this context, being the responsibility of the creator to define the whole flow of the project, which can be a difficulty when you are doing this flowchart without knowing what the project objectives are.

\subsection{Kanban, E-Kanban and Scrum}

Kanban as well as its electronic version came from the Toyota's production model when there was a need to record information and it had a definition to be executed, or if it had already been executed. The closest application of Kanban in the area of computing is the practice of software development using Scrum. Scrum is an agile methodology 
of software development context that has a screen with divisions to prioritize the important points of the project and streamline its production but guaranteeing high quality. This methodology is strongly applied in software and project management teams in a general way because the manager and those involved can get a sense of the whole project as it is happening, but also of its attributions [10].

An advantage of using Scrum is to work with the terms in the project to be implemented. But from another point of view, Scrum works with tasks and time, cannot absorb much information, is intended primarily for task management and leaves aspects of research projects that are relevant from the outside.

Image 1 is a comparative between the correlated frameworks and their due applications with digital tools to illustrate the field of action of each one and where this work proposes to contribute in the context of the production of research projects.

\section{Timeline}

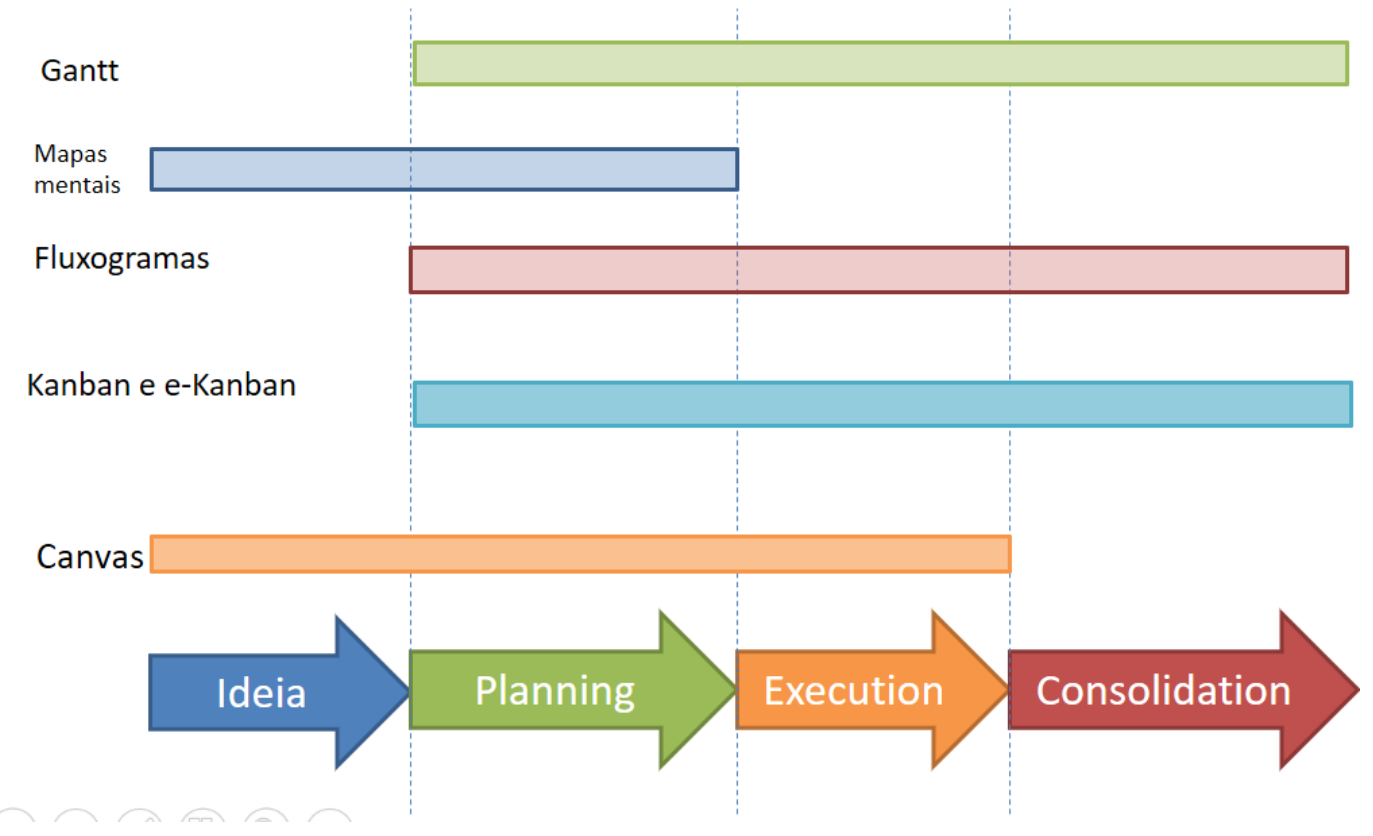

Image 1. Actuation point in timeline's project 


\section{Methodology}

In the postdoctoral work of the author Alexandre Osterwalder who came to turn the book "Business Model Generation", is described a correlated tool that contributes strongly with the intension of this project, since the authors propose a tool that can be worked in the management context for creating business in a less bureaucratic way than a business plan and more practice while managing a company.

The whole concept of this work is based on the defined business model "A business model describes the logic of creation, delivery and value capture by an organization [2] and when it comes to business management, the main tool used by a manager to generate new business or to reformulate an existing one, as well as the execution schedule, is the Business Plan, which is a document built by the product idealizers or the stakeholders. This document is done in a linear way, that is, filling each topic in order as the business premises are defined.

In order to build a business plan, considering that it is a team work, several, if not all, of the key points of the business plan must be defined in order to be able to compose the text, and for this starting point is ideal for all who participate, a general knowledge of the business that is sufficient to form a concrete and simple concept forming a common starting point among team members, as the author states. "We need to start all from the same point and talk about the same thing. The challenge is that this concept should be simple, relevant and intuitively understandable, while not oversimplifying the complexity of functioning. [2]. The business plan is critical in establishing business, industry, or product assumptions which will be built or undergoes restructuring. However, because it is a text, it presents difficulties for the members of the team responsible to fully visualize the business and future complications.

A screen is proposed, consisting of nine blocks defined according to the main needs of a business plan and the assumptions outside the business plan that it considers necessary to generate a new product, company or business or to restructure an existing one [2].

Using this strategy, we have an information visualization tool capable of summarizing all the fundamental aspects of a business on a screen, being possible to be visualized and shared with all the members of the team simultaneously assisting in the process of concept formation and decision.

To the strategy established works to make the Business Model Canvas, such as the Business Model Framework is commonly called, is need to use a frame projection on a canvas that is large enough for everyone in the team to view or print from frame on paper of sufficient size to view all.

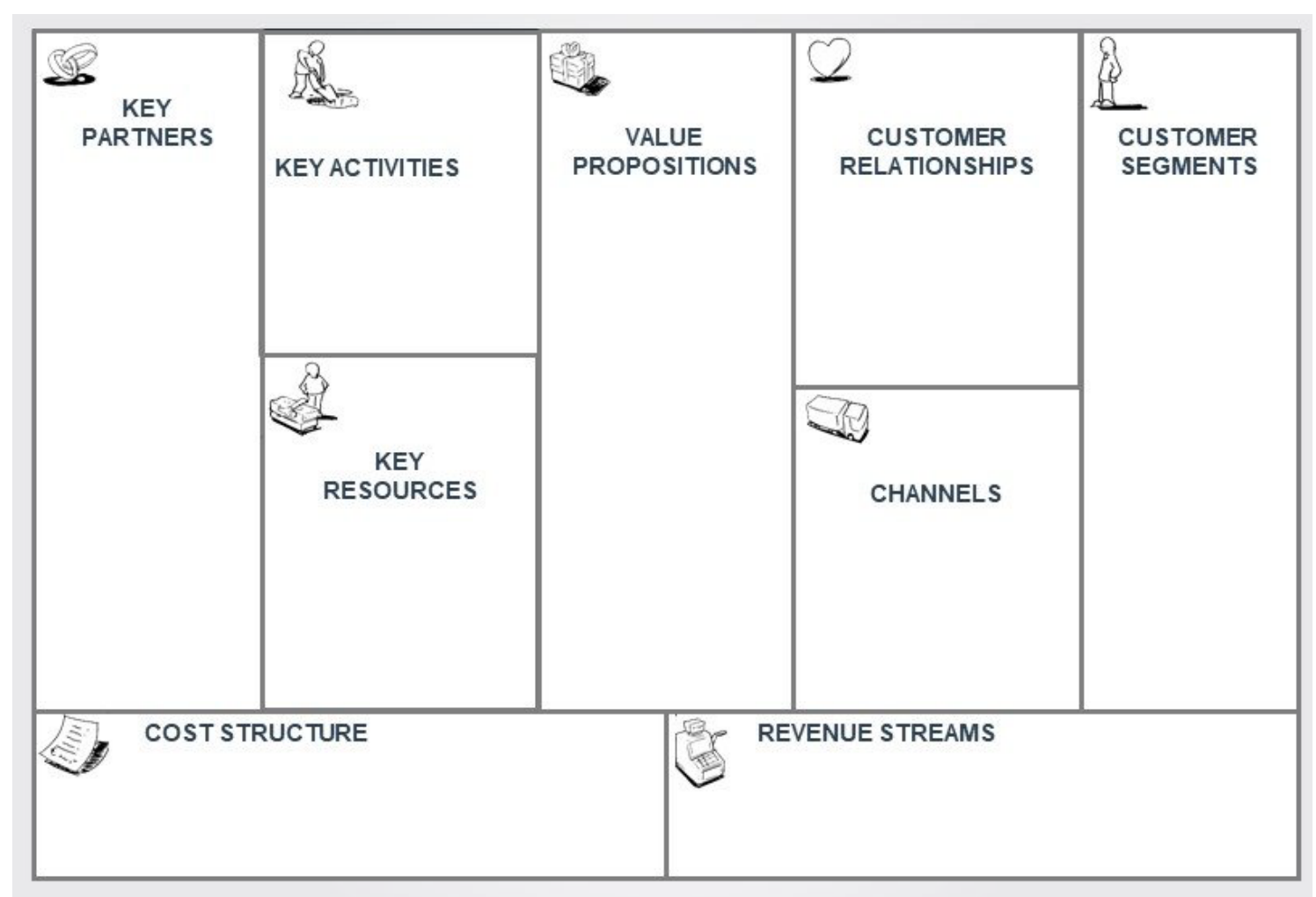

Image 2. Business Model Canvas 
The nine blocks that constitute the Canvas and its descriptions are:

Customer Segments: An organization serves one or several Customer Segments;

Value Proposition: A business or product seeks to solve the customer's problems and satisfy their needs with value propositions;

Channels: Value Proposals are delivered to customers through Channels of Communication, Distribution and Sales;

Customer Relationship: Customer Relationship is established and maintained with each Customer Segment;

Sources of Revenue: Sources of Revenue result from value propositions offered to customers successfully;

Main Features: The Main Features are the active elements to offer and deliver the elements previously described in the Value Proposition;

Key Activities: The main activities to be carried out by the company so that Value Proposals are delivered to the designated Client Segments.

Major Partnerships: Some activities are outsourced and some resources are acquired outside the company.

Cost Structure: Elements of the Business Model that generate costs are described in this field totaling the overall cost of the product / service.

In order to fill the Canvas content, it is proposed to use Post-itsTM that will be pasted in each Canvas field containing small phrases or keywords that concretely describe the concept corresponding to the field that is filled and can be removed or changed when the text contained in the post-it is no longer consistent with the business described. An example, is the field described as "Proposal of Value", where you must place the Post-itsTM containing the description of the product or company, such as the company Netflix for example, that would put in this field a Post-it with the following description "Unlimited movie rentals, without leaving home or fines, at no additional cost."

A secondary contribution to the creation of Canvas, which consists of examples of handling of problems found in Business Models. Using Canvas itself to deal with problems, just dividing it into different perspectives and trying to focus on each sector of the business pictured to be able to analyze it and find fault.

The Project Management Model Canvas is a work that the author used the Business Model Canvas adapting its knowledge and experience with existing tools and consolidated management methodologies [9].

The proposal of the Project Model Canvas is to integrate the project knowledge, its stages and get to present to all of the team with indifference of knowledge, because according to the author himself, the problem is not the team member to have knowledge or experience, but the starting point and the capacity of expansion of the knowledge that each has to reach the situation.

The problem is not in these professionals (those with professional certification) nor in their process of acquiring knowledge about project management. The fact is that the standard project plan template is not, and has never been, tailored to work in most organizations. [9]. Thus, there are not a few managers who produce artifacts from a traditional design plan only to meet protocol.

They fill in documents they largely do not know what they will serve for "[9].

Both models of Canvas are visual strategies that are based on the formation of a mental model and transcription for a screen. As stated [9] no one can get a project, just design models. A mental design model is composed of concepts - such as resources, stakeholders, deliverables, risks - and the relationships between these concepts. "And it reaffirms the relationship between the concepts that are worked on the framework as a mental model and not as a decision flowchart or a ticket table." It is important to clarify that the canvas is not a project flowchart, since a flowchart shows a sequence of steps, while the important thing on canvas are the relationships between concepts." [9]. 


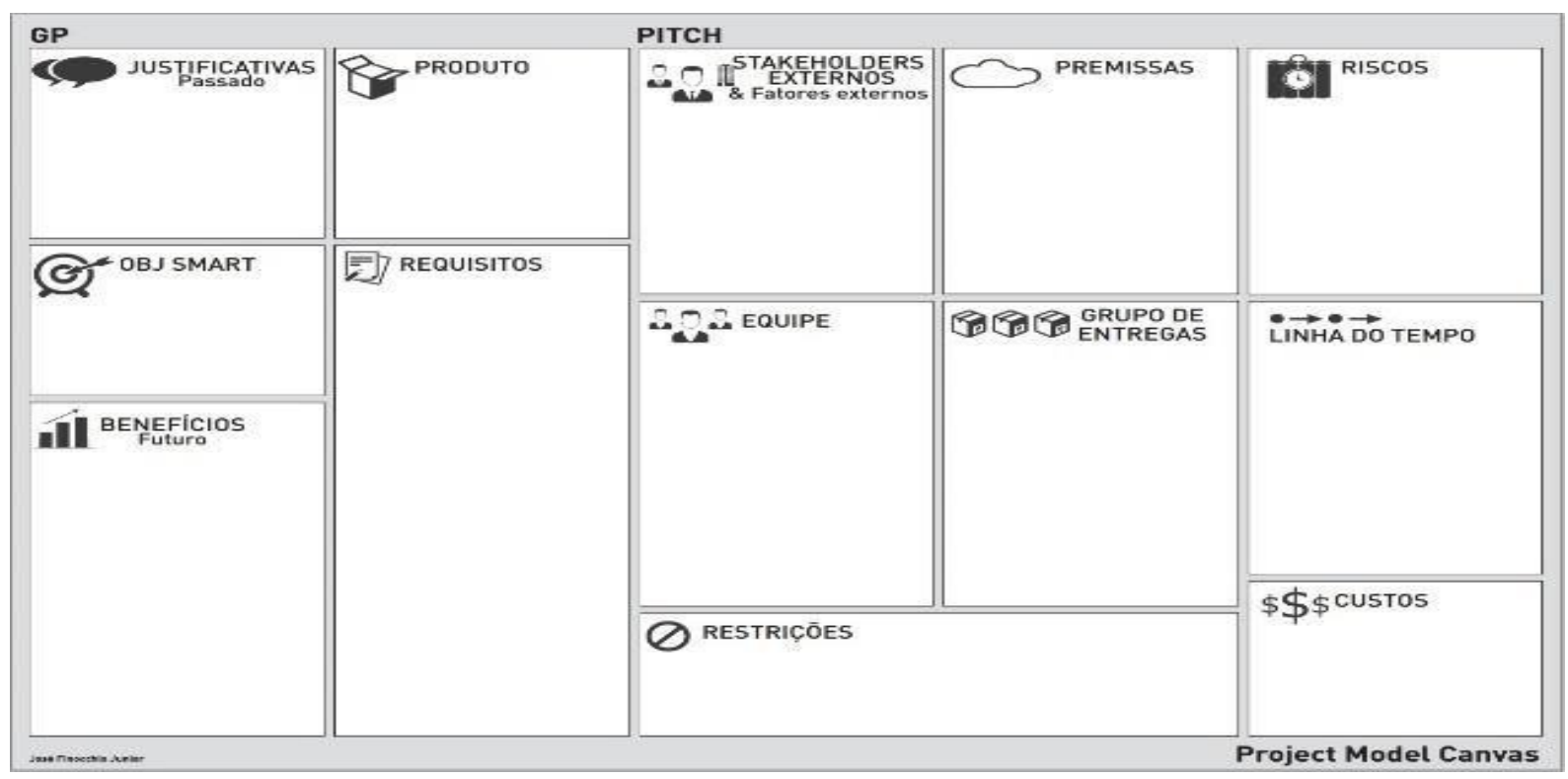

Image 3. Project Model Canvas

\section{Proposal}

The proposed Model Research Project Canvas takes a different approach from the standard models in two respects. The first one is that it is a visual and non-linear strategy of working information, whose fields are based on the concepts of a research project in a generalized way, to aid in the translation of the mental design model of the person who creates the transforming ideas into words and phrases that are recorded on the canvas and shared with the team. Second, it is recommended that the canvas be filled in the design of the project, that is, before it begins to happen to align the expectations, conditions and objectives of the whole team and project, avoiding that during its execution some aspect not predicted becomes a barrier to continuation and can be used throughout the project to validate if the actions are following as planned and to assist in the process of writing projects, theses and dissertations at the end of the project described on the canvas.

There are visual strategies to work with team information, project creation and management, which were presented to justify the choice of the canvas as a tool to help in the creation of academic research projects. Many of these strategies are not specific to the purpose of creating research projects or else make the creation process slow and tedious given such a need for prior knowledge of the methodology. In contrast, the canvas proposes a focus on aspects of an academic research project in an attempt to be assertive assisting at the time of creation and during the process of execution until finalization.

With the theoretical basis of the two existing canvases with the addition of the concepts of authors related to research methodologies, the following Project Research Project Canvas is composed of thirteen conceptual fields that answer the questions and stages as described [3].

\subsection{Identification of the Elements of a Research Project}

They are the usual components of a research project:

a) Formulation of the problem;

b) Construction of hypotheses or specifications of objectives;

c) Identification of the type of research;

d) Operation of the variables;

e) Selection of the sample;

f) Elaboration of the instruments and determination of the strategy of data collection;

g) Determination of the data analysis plan;

h) Forecasting the presentation of results;

i) Schedule of research execution;

j) Definition of the human, material and financial resources to be allocated

[2] presents a reference in this context, considering these ten items proposed by him to compose a research project with connection with other authors that base the project with basic questions and formation of key concepts, give rise to the Research Project Model Canvas. 


\begin{tabular}{|c|c|c|c|c|}
\hline Project__ & & GRVA & Date $\_-$ & Version \\
\hline \multirow[t]{2}{*}{$\begin{array}{l}\text { External \& } \\
\text { Social } \\
\text { Resources }\end{array}$} & \multirow[t]{2}{*}{ Intentionality } & \multirow[t]{2}{*}{$\begin{array}{l}\text { Proposal of } \\
\text { Social } \\
\text { Contribution }\end{array}$} & Social Impact & \multirow[t]{5}{*}{ Consolidation } \\
\hline & & & Issues & \\
\hline \multirow[t]{2}{*}{$\begin{array}{l}\text { Technological \& } \\
\text { Academic } \\
\text { Resources }\end{array}$} & \multirow[t]{2}{*}{$\begin{array}{l}\text { Conceptual } \\
\text { Basis }\end{array}$} & \multirow[t]{2}{*}{$\begin{array}{l}\text { Proposal of } \\
\text { Scientific } \\
\text { Contribution }\end{array}$} & & \\
\hline & & & Scientific Impact & \\
\hline Costs & $\begin{array}{l}\text { Financing / } \\
\text { Development }\end{array}$ & \multicolumn{2}{|r|}{ Team } & \\
\hline
\end{tabular}

Image 4. Research Project Model Canvas

The Research Project Template Canvas is composed of thirteen fields that are:

1. Proposal of Scientific Contribution

2. Proposal of Social Contribution

3. Scientific Impact

4. Social Impact

5. Issues

6. Consolidation

7. Conceptual Basis

8. Intentionality

9. Technological \& Academic Resources

10. External \& Social Resources

11. Costs

12. Financing / Development

13. Team

\section{Proposal of Scientific Contribution}

It is the contribution of the project, in which niche of scientific knowledge the project intends to add information. When a project is not intended to create or propose something, it can contribute scientifically to an analysis or metrication, since each segment has its need for research.

\section{Proposal of Social Contribution}

Answering the "whys" of doing a project can provide answers that justify what equipment, what problems will be worked, and so on. However, the specific field of the Social Contribution Proposal asks who is preparing the research project what the benefits generated by the research will be.
It is understood benefits by the results that the project aims to achieve, even if they are not positive aspect.

\section{Scientific Impact}

This field is aimed at the project on the side of the scientific community, from the point of view of who later the completion of the project will have as a basis for others or else extraction of information. This is the measurable and replicable part that the project can have when it is completed.

\section{Social Impact}

What the social impact seeks to highlight in the project is the question "What will happen to the niche affected by the project when the Social Contribution Proposal is completed?", That is, from the conclusion of the project it will affect.

\section{Issues}

This field is positioned visually between the two impacts that the project may provoke with the intention of capturing the context that is delimiting, which will not be worked or is not in the hands of the creators and executors of the project to be determined.

\section{Consolidation}

In the mental model of creation the first items to be formulated in the creation of a project are the intentionality and the consolidation, because one thinks in what one 
wants to create and how this creation will be to the end of the project. The chart helps to become aware of the other points between the intention of the project and what it will produce or how it will take shape.

To better fill this field it is interesting to answer the questions "What will be built?", "How will this work be exposed to the public?", "What palpable evidence will be generated at the end of the project?".

\section{Conceptual Basis}

A good relationship of this field with the practice of scientific research is to relate the terms of the "conceptual base" field with the methods of RSL - that are based on scientific searches using combinations of key terms to search for articles related to the subject.

This canvas field asks the researcher what the main concepts he will work on the project, which also serves to describe the source of information that the project will seek.

\section{Intentionality}

Intentionality is the closest field on the canvas of gross idea, brainstorming, and the need to solve a problem. This field is strongly related to the motivation to create the project, the justification for which the other fields will be consequently filled. One of the ways to understand what to put in this space is to answer the questions "Why this project should be done", "What action is needed to solve the problem?", "What is missing or discrepant that prevents the situation of be positive?"

\section{Technological \& Academic Resources}

A research project starts with at least one orienting, an advisor and an idea, and as it is necessary or viable other parts are composing this project. Within a survey it may be necessary to have the help of a laboratory technician, the follow-up of a co-supervisor, the access to a specific laboratory of the institution. These and other items are described in this field to predict what will need to be provided within the institution for the research project to be executed by making it clearer what each staff member will be tasked to achieve.

\section{External \& Social Resources.}

Each research context requires different resources such as working with people in the research requires the approval of the local ethics committee, or when working with statistical research, you need to recruit people to participate in the research or a database external to the research environment to compose the project.

This field asks the project's creator what their needs are outside the search environment and the social resources that are needed. External resources are understood to be all that the researcher predicts according to the objectives to be achieved that he will need to reach the end.

\section{Costs}

This field as well as the others present in the bottom line of the canvas have an administrative character of the project and depend heavily on the filling of the other fields so that they are filled in a proper way.

This field analyzes all the previously listed resources, external, social, technological and academic as well as the field of the team to be able to describe about financial resources, which will be necessary to execute the project. Including in this way acquisition of items and payment of scholarships, salaries and other expenses.

\section{Financing and Development}

In this field it is necessary to describe what institution or source of financing the project will have, even if it is not financial resources but technology or physical space is interesting to be described. There are cases that projects are commissioned by companies for educational institutions to do the project and provide financial and technological resources leaving the institution in charge of providing physical space for example.

It may be that a project does not have any source of funding but needs resources, this field may be blank in these cases.

\section{Team}

As mentioned before, a research project has at least two people involved, the guiding and the guiding, and others have a whole team, this field is intended to describe them with their respective functions. In order to be objective, it is recommended to put only those directly involved with the project, those people who will be executing, reviewing and in a generic way "put their hand in the mass" because those involved indirectly should be described in the External Resources \& Social Resources.

\section{Results and Discussion}

The composition of frameworks to form the Research Projects Model Canvas brought to the discussion the ability of an analog tool (paper) to be efficient in the process of generating ideas and creating projects considering the use by a team. So the first result obtained from the application tests of the tool, carried out with graduate students in the process of completion, was the need for a digital and online tool so that physically distant teams could communicate with the same tool to work on the mental model of the project.

Using the same post-itTM parameters and Canvas, a web tool was developed to use the framework developed with basic design and implementation of the main canvas activities, to add items to the post-itTM, to move it and to edit its contents when necessary. 


\begin{tabular}{|c|c|c|c|c|}
\hline Project__ & & DGrva & Date $\_\_$ & Version \\
\hline \multirow{3}{*}{$\begin{array}{l}\text { External \& } \\
\text { Social } \\
\text { Resources }\end{array}$} & Intentionality & \multirow{3}{*}{$\begin{array}{l}\text { Proposal of } \\
\text { Social } \\
\text { Contribution }\end{array}$} & Social Impact & \multirow[t]{6}{*}{ Consolidation } \\
\hline & FIRST NOTE & & & \\
\hline & & & Issues & \\
\hline \multirow[t]{2}{*}{$\begin{array}{l}\text { Technological \& } \\
\text { Academic } \\
\text { Resources }\end{array}$} & \multirow[t]{2}{*}{$\begin{array}{l}\text { Conceptual } \\
\text { Basis }\end{array}$} & \multirow[t]{2}{*}{$\begin{array}{l}\text { Proposal of } \\
\text { Scientific } \\
\text { Contribution }\end{array}$} & & \\
\hline & & & Scientifie Impaet & \\
\hline Costs & $\begin{array}{l}\text { Financing / } \\
\text { Development }\end{array}$ & \multicolumn{2}{|r|}{ Team } & \\
\hline
\end{tabular}

Image 5. Webtool applying Research Project Model Canvas

Secondly, researcher's preferences between visual and textual strategies for project creation and understanding were measured, revealing that $78 \%$ prefers a visual strategy to conceive ideas and assimilate them rather than text strategies. It was also found that in the context of researchers in the area of computing and related, $83 \%$ are familiar with agile development methodologies, auxiliary tools for project creation. While in the areas of human sciences less than $30 \%$ knew some tool or model of project creation or development of them. Just as more than $60 \%$ demonstrated that they did not know project models other than the document structure of theses and dissertations of the institution.

These data reveal that the Research Project Model Canvas tends to meet the demand for project creation across a broad spectrum of knowledge areas and assist in the process of creating and interpreting project concepts to the extent of generically leveling a student in creating projects independent of their previous experience.

At a given moment of the application test of the digital tool the researchers indicated difficulty in initially understanding the methodology of the Canvas of Research Project Model, but which, when practicing the use and preferably in a team, makes the learning process smoother and more natural.

\section{Conclusions}

The integration of a visual methodology with agile methodologies of development in the tool that was presented in this work makes the creation process less dependent on a talent or idea and provides when searching a standard way to format a project in such a way that the understanding of the project and its steps by the team before it begins its execution.

As well as, the interpretation of the information of a project arranged in the Research Project Template Canvas are of better and faster understanding when comparing with the reading of a complete manuscript.

\section{REFERENCES}

[1] BEHAR, P. A. Modelos Pedagógicos em Educação à Distãncia. Artmed 2009.

[2] OSTERWALDER, A. Business Model Generation Inovação em Modelos de Negócios: um manual para visionários, inovadores e revolucionários - Rio de Janeiro, RJ: Alta Books, 2011.

[3] GIL, A. C. Como elaborar Projetos de Pesquisa - 4 ed - São Paulo - SP. Atlas, 2002.

[4] Instituto de Gerenciamento de Projetos (PMI). Um Guia do Conjunto de Conhecimentos em Gerenciamento de Projetos: Guia do PMBOK, 3a. edição, 2004, PMI.

[5] RUDIO, F. V. Introdução ao projeto de pesquisa científica. Petrópolis. Vozes - 2007.

[6] MAXIMIANO, A. C. A. Aplicação do pmbok a projetos acadêmicos. III semeAd (Seminários em Administração FEA - USP), São Paulo, Brasil, v.1, 1998. 
[7] BUZAN, T. The mind map book: Unlock your creativity, boost your memory, change your life .2010 - Pearson BBC Active New York.

[8] PFLEEGER, S.L. Engenharia de Software: Teoria e Prática. São Paulo: Prentice Hall, $2^{\text {a }}$ edição, 2004.

[9] FINOCCHIO, J. Project Model Canvas: gerenciamento de projetos sem burocracia - 1 ed - Rio de Janeiro. Elsevier, 2013.

[10] SUGIMORI, Y., et al. "Toyota production system and kanban system materialization of just-in-time and respect-for-human system." The International Journal of Production Research15.6 (1977): 553-564. 